\title{
"Petal effect"-inspired superhydrophobic and highly adhesive coating on magnesium with enhanced corrosion resistance and biocompatibility
}

\author{
Feng Peng ${ }^{1,2}$, Donghui Wang ${ }^{1,2}$, Xiaohan $\mathrm{Ma}^{1}$, Hongqin Zhu ${ }^{1}$, Yuqin Qiao ${ }^{1}$ and Xuanyong Liu ${ }^{1 *}$
}

\begin{abstract}
With properties of complete degradation and favorable mechanical behavior, $\mathrm{Mg}$ and its alloys are regarded as the next generation medical metal materials. However, fast degradation and poor surface biocompatibility hinder their clinical applications. Inspired by the "petal effect", we successfully constructed a superhydrophobic and highly adhesive coating on pure Mg via a simple hydrothermal treatment in a solution containing sodium oleate. The superhydrophobicity of the fabricated coating results from its flake-like micro-nanostructure and the low-surface-energy oleate group. Water droplet on the superhydrophobic coating cannot roll off even when the sample is turned upside down, owing to the sealed air-pockets and the van der Waals' attraction at the solidliquid interface, indicating a highly adhesive force. The chemical and mechanical stability of the superhydrophobic coating were measured. Potentiodynamic polarization and electrochemical impedance spectroscopy measurements suggest enhanced corrosion resistance of the as-prepared sample. Furthermore, cell cytotoxicity, migration and adhesion data of human umbilical vein endothelial cells (HUVECs) reveal an improved cytocompatibility of the modified surface. Finally, hemolysis assay and platelet adhesion assay suggest an improved hemocompatibility. It is believed that the facile and low-cost method can expand the new application of superhydrophobic surface with highly adhesive on $\mathrm{Mg}$ in biomedical fields.
\end{abstract}

Keywords: magnesium, petal-effect, superhydrophobic, corrosion resistance, biocompatibility

\section{INTRODUCTION}

Magnesium $(\mathrm{Mg})$ based materials are attracting much attention and are regarded as the next generation biomedical metal materials $[1,2]$. Mg is a necessary and important trace metal element within human body, playing important roles in protein and nucleic acid synthesis, as well as many other cellular functions. Originating from its low standard electrode potential $(-2.37 \mathrm{~V} v s$. normal hydrogen electrode), $\mathrm{Mg}$ can totally degrade via corrosion and the intermediate corrosion product can be either absorbed or metabolized in the form of $\mathrm{Mg}^{2+}$. More importantly, Mg possesses appropriate mechanical strength that is close to cortical bone, which may reduce stress shielding. However, fast degradation and poor surface biocompatibility hinder its clinical application. Many efforts have been devoted to improving $\mathrm{Mg}$ alloys' corrosion resistance and their biological performance via surface modifications, such as plasma electrolytic oxidation coating [3], apatite coating [4] and organic polymer coating [5]. However, none of the coatings mentioned above can separate the corrosive aqueous from the material. Once $\mathrm{Mg}$ or the degradable coating contacts with aqueous environments, the corrosion begins. Bearing this situation in mind, fabricating a superhydrophobic surface on $\mathrm{Mg}$ alloys could effectively reduce the contact area between the material and corrosive aqueous medium, leading to an improved corrosion resistance.

However, a superhydrophobic surface with water-repellent property is not suitable for cell adhesion. Nature is an excellent school for academic research. In 2008, inspired by the petal of red rose, Feng et al. [6], for the first time, defined the superhydrophobic surface with highly adhesive as "petal effect". A water droplet on such surface

\footnotetext{
${ }^{1}$ State Key Laboratory of High Performance Ceramics and Superfine Microstructure, Shanghai Institute of Ceramics, Chinese Academy of Sciences, Shanghai 200050, China

${ }^{2}$ University of Chinese Academy of Sciences, Beijing 100049, China

* Corresponding author (email: xyliu@mail.sic.ac.cn)
} 
cannot roll off even when the surface is turned upside down. Up to now, the study of superhydrophobic and highly adhesive surface is limited in the potential application of no-loss liquid transfer $[7,8]$. Water on such a surface is not totally repellent, but half is contact with the surface and the other is sealed with air. The contact area between solution and surface is favorable for cell adhesion. Bearing these situations in mind, constructing a superhydrophobic surface with highly adhesive on $\mathrm{Mg}$ alloy might achieve a balance between the corrosion resistance and cell adhesion, providing a new surface modification direction on $\mathrm{Mg}$ alloy for clinical application.

A rough surface and low surface energy are the two key elements for the design of superhydrophobic surface [9]. The water adhesive force of superhydrophobic surface varies with its structural characteristics [10]. A close array of micropapillae endows the surface of the petal of red rose a superhydrophobic ability with highly adhesive force. Hu et al. [11] regulated the adhesive force from 4.4 to $89.6 \mu \mathrm{N}$ continuously on $1 \mathrm{H}, 1 \mathrm{H}, 2 \mathrm{H}, 2 \mathrm{H}$-perfluorooctyltriethoxysilane-modified $\mathrm{TiO}_{2}$ nanotube arrays by changing the structural characteristics, such as tubular diameter, length and density. On the other hand, our previous study reported that nanoflake-like structure consisting of $\mathrm{Mg}(\mathrm{OH})_{2}$ and $\mathrm{Mg}$ - $\mathrm{Al}$ layered double hydroxide (LDH) could effectively enhance the corrosion resistance and biocompatibility of $\mathrm{Mg}$ alloy [12]. Inspired by the petal effect, if we further fabricate the surface with a low surface energy composition, the micro-flake-like structure may act as the micropapillae, resulting in the superhydrophobic surface with highly adhesive.

LDHs are made up of positively charged brucite-like layers and an interlayer region containing various anions and solvation molecules $[13,14]$. Thus, it is possible to bond inorganic anions with low surface energy on the surface of positively charged layer. In addition, sodium oleate (SO), usually working as a surfactant, is a low surface energy material with excellent biocompatibility [15]. Chen et al. [16] successfully modified ultralong hydroxyapatite nanowires with $\mathrm{SO}$ and obtained a superhydrophobic surface with self-cleaning and oil/water separation abilities. Considering these context, it is promising to fabricate a superhydrophobic surface with highly adhesion on $\mathrm{Mg}$ alloy for biomedical applications.

In this work, a superhydrophobic surface with highly adhesion was prepared on pure $\mathrm{Mg}$ via facile, low-cost, one-step hydrothermal treatment. The formation mechanism of the superhydrophobic surface was investigated. Moreover, the chemical and mechanical stability, corrosion resistance, cytocompatibility and hemocompatibility of the superhydrophobic surface were measured.

\section{EXPERIMENTAL SECTION}

\section{Sample preparation}

The dimension of pure $\mathrm{Mg}$ specimens was $10 \mathrm{~mm} \times$ $10 \mathrm{~mm} \times 2 \mathrm{~mm}$. Before the hydrothermal treatment process, the specimens were polished with a series of $\mathrm{SiC}$ abrasive paper (up to 1000 grit), ultrasonically cleaned in ethyl alcohol for $10 \mathrm{~min}$, and dried in the air.

The hydrothermal treatment process was performed according to our previous work [12]. In a typical process, the $\mathrm{Mg}$ specimens were placed in Teflon liners with different reaction solutions at $120^{\circ} \mathrm{C}$. The reaction solutions contained $50 \mathrm{~mL}$ aluminum nitrate solution $\left(0.02 \mathrm{~mol} \mathrm{~L}^{-1}\right)$, adding $600 \mu \mathrm{L} \mathrm{NaOH}\left(10 \mathrm{~mol} \mathrm{~L}^{-1}\right)$ to adjust the $\mathrm{pH}$ value, and different $\mathrm{SO}$ concentrations $(0,200$, 400,800 , and $1200 \mu \mathrm{mol} \mathrm{L}^{-1}$, respectively). The reaction time varied from 3 to $24 \mathrm{~h}$.

\section{Sample surface characterization}

The surface and cross-sectional morphology of the samples were observed by scanning electron microscopy (SEM, Hitachi-S3400N, Hitachi, Japan), and surface elemental compositions of the samples were evaluated by energy dispersive spectrometry (EDS, IXRF-550i, IXRF SYSTEMS, USA). Meanwhile, scanning maps $(\mathrm{Mg}, \mathrm{O})$ of cross-section of $\mathrm{LDH}$ and $\mathrm{LDH} / \mathrm{SO}$ samples were also measured by EDS.

The phase compositions of $\mathrm{Mg}, \mathrm{LDH}$ and $\mathrm{LDH} / \mathrm{SO}$ samples were analyzed by X-ray diffraction (XRD, D/ Max, RIGAKU, Tokyo, Japan). The chemical states of surface elements were measured by X-ray photoelectron spectroscopy (XPS, PHI-5000C ESCA system PerkinElmer, USA). Fourier transform infrared (FTIR) spectra were recorded using a FTIR spectrometer (FTIR-7600, Lambda Scientific, Australia).

The water contact angles (CAs) were measured on an optical contact angle system (Model SL200A/B/D) at ambient temperature using a $3 \mu \mathrm{L}$ deionized water droplet.

\section{Chemical and mechanical stability}

For the chemical stability evaluation, deionized water with a series of $\mathrm{pH}$ value (1-13) was used in the test. The $\mathrm{pH}$ value of deionized water was adjusted by $0.1 \mathrm{~mol} \mathrm{~L}^{-1}$ $\mathrm{NaOH}$ or $\mathrm{HCl}$. The CAs of the water with different $\mathrm{pH}$ values on $\mathrm{LDH} / \mathrm{SO}$ samples were measured as mentioned 
above.

For the mechanical stability evaluation, the LDH/SO samples were dragged to move on 1000 grit $\mathrm{SiC}$ abrasive paper in one direction under a pressure of $2.45 \mathrm{kPa}$. The changes of the CAs with sliding distance were measured.

\section{Electrochemical tests}

The corrosion resistance of $\mathrm{Mg}, \mathrm{LDH}$ and $\mathrm{LDH} / \mathrm{SO}$ was evaluated by potentiodynamic polarization tests and electrochemical impedance spectroscopy (EIS) via a CHI760C electrochemical analyzer (Shanghai, China) in phosphate buffer saline (PBS) at $37^{\circ} \mathrm{C}$. Both processes were conducted in a three-electrode electrochemical cell with a saturated calomel electrode (SCE) as the reference electrode, a graphite rod as the counter electrode and the sample with exposing area of $0.255 \mathrm{~cm}^{2}$ as the working electrode. Ahead of the test, the samples were stabilized in PBS for 400 seconds. The test of potentiodynamic polarization was conducted at a scanning rate of $10 \mathrm{mV} \mathrm{s}^{-1}$. The corrosion potential $\left(E_{\text {corr }}\right)$, current density $\left(i_{\text {corr }}\right)$ and corrosion resistance $\left(R_{\mathrm{p}}\right)$ were calculated according to Tafel extrapolation. For the test of EIS, the amplitude of sinusoidal perturbing was $5 \mathrm{mV}$, and the frequency varied from $100 \mathrm{kHz}$ to $10 \mathrm{mHz}$. The DC voltage applied for the EIS tests was open circuit potential. The EIS results were analyzed with ZViewTM software. Both potentiodynamic polarization test and EIS tests were performed under air condition with steady air pressure and temperature.

\section{Immersion test}

The $\mathrm{Mg}, \mathrm{LDH}$ and $\mathrm{LDH} / \mathrm{SO}$ samples were immersed in $\mathrm{PBS}$ at $37^{\circ} \mathrm{C}$ for one month to evaluate their long-term corrosion resistance. Each sample was placed inside a tube containing $40 \mathrm{~mL}$ PBS. After one month, all the samples were cleaned by chromic acid solution $\left(200 \mathrm{~g}\right.$ of $\mathrm{CrO}_{3}$ and $10 \mathrm{~g}$ of $\mathrm{AgNO}_{3}$ per liter of water). The mass loss of each sample was measured by electronic balance (AL204-IC Mettler Toledo) and the surface morphology was taken by a digital camera.

\section{Cell migration}

Human umbilical vein endothelial cells (HUVECs, ScienceCell, USA) were used to evaluate the cytocompatibility (cytotoxicity, cell proliferation and adhesion) of the $\mathrm{Mg}, \mathrm{LDH}$ and $\mathrm{LDH} / \mathrm{SO}$ samples. The cells were cultured with endothelial cell medium (ECM) at $37^{\circ} \mathrm{C}$ in a humidified atmosphere of $5 \% \mathrm{CO}_{2}$ in air. Cells mentioned in this work are referred to HUVECs, if not specified. All the samples were sealed by water-proof silica gel, leaving one side for the following cell tests, and sterilized via ultra- violet irradiation over $12 \mathrm{~h}$.

The samples were incubated in ECM for $24 \mathrm{~h}$ with a sample-area/extraction-medium ratio of $0.25 \mathrm{~cm}^{2} \mathrm{~mL}^{-1}$. At the same time, $1 \mathrm{~mL}$ of cell suspensions with a cell density of $2 \times 10^{5}$ cell $/ \mathrm{mL}$ were added to each well of a 24 well culture plate. After 1 day, lines crossing the cell well were drawn by a $200 \mu \mathrm{L}$ pipet tip, and the culture medium was replaced with $1 \mathrm{~mL}$ extraction. After cells migrating $9 \mathrm{~h}$, the actin were stained with fluorescein isothiocyanate (FITC)-phalloidin (Sigma, USA) and nuclei were stained with 4',6-diamidino-2-phenylindole (DAPI, Chemical International). Subsequently, the cells were observed via fluorescence microscopy (Olympus, Japan) and the numbers of cells migrating into the crossing line were counted.

\section{Cytotoxicity evaluation}

The extracted solution, obtained as mentioned in the previous section, was designated as $100 \%$, and diluted to $60 \%$ and $30 \%$ with ECM. $100 \mu \mathrm{L}$ cell suspensions with a cell density of $5 \times 10^{4}$ cell $/ \mathrm{mL}$ were added to each well of a 96-well culture plate. After $24 \mathrm{~h}$, the culture medium was replaced by $100 \mu \mathrm{L}$ extracted solution with different concentrations and cells were incubated for another one day. ECM without extract served as the control group. Cell number was tested by the alamarBlue assay (AbD Serotec Ltd, UK) according to the manufacturer's instruction. The cell viability was calculated by the following equation:

$$
\text { Viability }=\frac{F_{\mathrm{s}}}{F_{\mathrm{c}}} \times 100 \% \text {, }
$$

where $F_{\mathrm{s}}$ is the fluorescence intensity of the sample group and $F_{\mathrm{c}}$ is the fluorescence intensity of the control group.

\section{Cell adhesion with direct incubation}

The cells were seeded on the samples with a density of $5 \times$ $10^{4}$ cells $/ \mathrm{mL}$. After culturing 1, 4 and $24 \mathrm{~h}$, the samples were rinsed with PBS. Then the cells were fixed, permeabilized and blocked successively by $4 \%$ paraformaldehyde (PFA) diluent, $0.1 \%(v / v)$ Triton X-100 (Amresco, USA) and $1 \mathrm{wt} . \%$ bovine serum albumin (BSA, Sigma, USA) respectively. Shortly afterwards, FITCphalloidin was added to stain F-actin, and DAPI to stain nucleus. The samples were rinsed with PBS after each step. Finally, the samples were observed by confocal laser scanning microscopy (CLSM, Leica SP8, Germany).

\section{Platelet adhesion}

Platelet-rich plasma (PRP) was prepared by centrifuging (1500 rmp, $15 \mathrm{~min}$ ) human whole blood. $50 \mu \mathrm{L}$ PRP was 

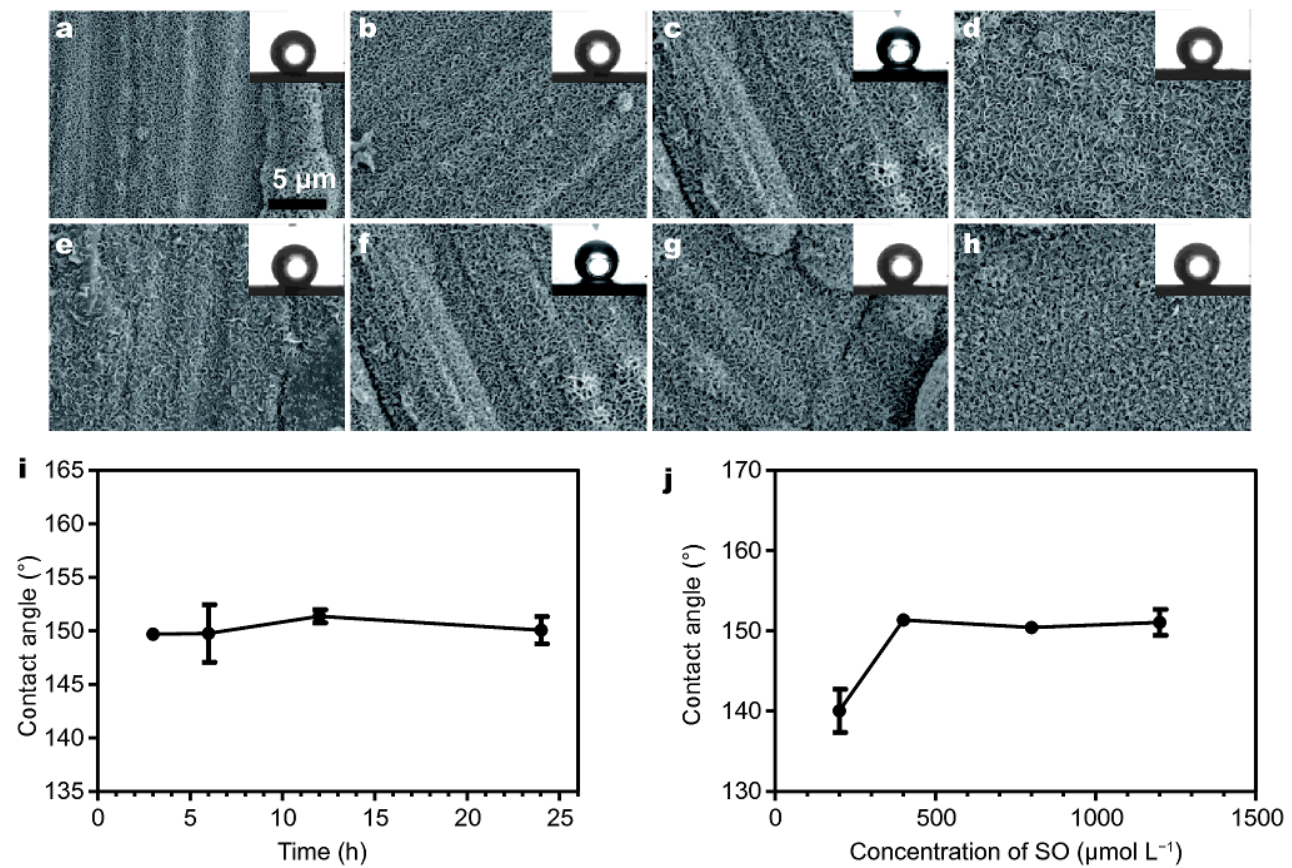

Figure 1 SEM images and (inset) water angles of the as-prepared superhydrophobic surfaces reacted for different reaction time with a SO concentration of $400 \mu \mathrm{mol} \mathrm{L}^{-1}$ : (a) 3, (b) 6, (c) 12, and (d) $24 \mathrm{~h}$. SEM images and (inset) water angles of the as-prepared superhydrophobic surfaces reacted for $12 \mathrm{~h}$ with different SO concentrations: (e) 200, (f) 400, (g) 800, and (h) $1200 \mu \mathrm{mol} \mathrm{L}^{-1}$. CA varies with reaction time (i) and SO concentration (j) (mean $\pm \mathrm{SD}, \mathrm{N}=3$ ).

added to the surface of the sample and incubated for $2 \mathrm{~h}$ at $37^{\circ} \mathrm{C}$. After washing with $0.9 \%(w / v)$ sodium chloride solution $(\mathrm{NaCl})$, the samples were fixed with $2.5 \%$ glutaraldehyde. The samples were then dehydrated in a gradual ethanol series $(30,50,75,90,95$, and $100 \% v / v)$ for $10 \mathrm{~min}$, respectively. The platelets adhering on the surface of the sample were detected by SEM.

\section{Hemolysis assay}

Human venous blood was collected from healthy young volunteers. Blood $(4 \mathrm{~mL})$ was diluted with $0.9 \%(w / v)$ $\mathrm{NaCl}(5 \mathrm{~mL})$. The samples were immersed in $1.5 \mathrm{~mL} 0.9 \%$ $(w / v) \mathrm{NaCl}$ for $30 \mathrm{~min}$ at $37^{\circ} \mathrm{C}$. Untreated $0.9 \%(w / v)$ $\mathrm{NaCl}$ and distilled water were served as negative and positive controls, respectively. After that, $30 \mu \mathrm{L}$ diluted blood was added to the samples. After incubated for another $60 \mathrm{~min}$ at $37^{\circ} \mathrm{C}$, the solutions were centrifuged for $5 \mathrm{~min}$ at $3000 \mathrm{rpm}$. The optical density of the supernatant was measured at $545 \mathrm{~nm}$ to determine the released hemoglobin. The hemolysis rate (HR) was calculated via the following equation:

$$
\mathrm{HR}=\frac{\mathrm{AS}_{545}-\mathrm{AN}_{545}}{\mathrm{AP}_{545}-\mathrm{AN}_{545}} \times 100 \%,
$$

where $\mathrm{AS}_{545}$ is the absorption value of the samples, $\mathrm{AN}_{545}$ is the absorption value of the negative control, and $\mathrm{AP}_{545}$ is the absorption value of the positive control.

\section{Statistical analysis}

Statistically significant differences $(p)$ between various groups were measured using one-way analysis of variance and Tukey's multiple comparison tests on a GraphPad Prism 5 statistical software package. All the data are expressed as the mean \pm standard deviation (SD). A value of $p<0.05$ was considered to be statistically significant and denoted as “*”, $p<0.01$ was “**”, and $p<0.001$ was “***”.

\section{RESULTS AND DISCUSSION}

\section{Effect of hydrothermal treatment time and SO concentration on the morphology and wettability}

Fig. 1a-d display the SEM images of the as-prepared surfaces in $400 \mu \mathrm{mol} \mathrm{L}^{-1} \mathrm{SO}$ for different time. Though reaction time varies, all the surfaces show compact nanoflake-like structure, which is in agreement with the traditional alkali heat treated surface structure [17-19]. The only difference is that with the increase of reaction time, the nanoflake-like structure grows up. The corresponding surface elemental compositions are shown in Table 1. The contents of $\mathrm{C}$ are almost the same, while the content of $\mathrm{Al}$ increases with the extension of reaction 
Table 1 Surface elemental compositions of coated samples prepared in different reaction conditions measured by EDS (corresponding with figure, mean $\pm \mathrm{SD}, N=3$ )

\begin{tabular}{ccccc}
\hline & $\mathrm{C}(\mathrm{wt} . \%)$ & $\mathrm{O}(\mathrm{wt} . \%)$ & $\mathrm{Mg}(\mathrm{wt} . \%)$ & $\mathrm{Al}(\mathrm{wt} . \%)$ \\
\hline $3 \mathrm{~h}$ & $25.95 \pm 0.75$ & $23.07 \pm 0.68$ & $49.74 \pm 0.03$. & $1.25 \pm 0.06$ \\
$6 \mathrm{~h}$ & $27.08 \pm 0.33$ & $41.60 \pm 0.03$ & $29.34 \pm 0.37$ & $1.99 \pm 0.07$ \\
$12 \mathrm{~h}$ & $23.43 \pm 0.86$ & $48.53 \pm 0.53$ & $25.73 \pm 0.23$ & $2.32 \pm 0.11$ \\
$24 \mathrm{~h}$ & $26.43 \pm 1.00$ & $47.67 \pm 0.32$ & $23.14 \pm 0.83$ & $2.761 \pm 0.15$ \\
$200 \mu \mathrm{mol} \mathrm{L}^{-1}$ & $17.59 \pm 2.54$ & $53.01 \pm 1.60$ & $27.17 \pm 0.76$ & $2.15 \pm 0.19$ \\
$400 \mu \mathrm{mol} \mathrm{L}^{-1}$ & $23.43 \pm 0.86$ & $48.53 \pm 0.53$ & $25.73 \pm 0.23$ & $2.32 \pm 0.11$ \\
$800 \mu \mathrm{mol} \mathrm{L}^{-1}$ & 36.500 .37 & $39.56 \pm 0.27$ & $21.65 \pm 0.29$ & $2.30 \pm 0.05$ \\
$1200 \mu \mathrm{mol} \mathrm{L}^{-1}$ & $43.46 \pm 0.67$ & $34.69 \pm 0.26$ & $19.19 \pm 0.56$ & $2.65 \pm 0.15$ \\
\hline
\end{tabular}

time. It indicates that the concentration of SO group on the sample surface does not change, while the coating thickness increases with the extension of reaction time. Fig. 1e-h display the surface morphology of the as-prepared surfaces with different concentrations of SO for $12 \mathrm{~h}$. The basic morphology of the sample surfaces is also compact nanoflake-like structure. With increased concentration of $\mathrm{SO}$, the nanoflake-like structure becomes more intensive and smaller, implying that high SO concentration will hinder the growth of crystal. In contrast to the trend that $\mathrm{C}$ and $\mathrm{Al}$ content vary with reaction time, the $\mathrm{C}$ content increases with the increase of SO concentration, while $\mathrm{Al}$ content almost unchanged. It means that, more $\mathrm{SO}$ in the reaction solution will result in more SO group binding on the sample surface. However, the coating thickness does not change with SO concentration.

As shown in Fig. 1i, the CAs of all the samples reached $150^{\circ}$, and change slightly with the reaction time. The CA was about $140^{\circ}$ for the reaction solution only containing $200 \mu \mathrm{mol} \mathrm{L}^{-1}$ SO (Fig. 1j). Once the SO concentration reached or over $400 \mu \mathrm{mol} \mathrm{L}{ }^{-1}$, the CA was stable above $150^{\circ}$. It is easy to conclude that the CAs varies with the SO concentration, but not with the reaction time. In addition, the water droplet does not slide even when the LDH/SO sample is tilted vertically (Fig. 2a) or turned upside down (Fig. 2b), indicating a highly adhesive force.

\section{Coating characteristics, formation mechanism and mechanism of the superhydrophobicity}

On the basis of the analysis of the effects of reaction time and $\mathrm{SO}$ concentration on the morphology and wettability, an reaction time of $12 \mathrm{~h}$ and SO concentration of $400 \mu \mathrm{mol} \mathrm{L}^{-1}$ (denoted as LDH/SO) were chosen as the optimal parameters to fabricate the superhydrophobic surface, and the control group without SO was denoted as LDH.

Fig. $2 c$ displays the XRD patterns of the samples. In the pattern of $\mathrm{Mg}$, only feature peaks of $\mathrm{Mg}$ are observed.
Both $\mathrm{Mg}(\mathrm{OH})_{2}$ (feature peak at $18^{\circ}$ ) and $\mathrm{Mg}$ - $\mathrm{Al} \mathrm{LDH}$ (feature peak at $12^{\circ}$ ) are detected in the pattern of $\mathrm{LDH}$ sample [20,21], which is consistent with our previous study [12]. Compared with the LDH sample, there is no obvious change of the crystallinity of LDH/SO sample. According to the result of EDS (Table 1), it is definite that oleate groups exist on the surface of $\mathrm{LDH} / \mathrm{SO}$ sample. Since SO is an amorphous organic matter and oleate groups only exist on the outermost of the coating, it does not show any peak in the XRD pattern of LDH/SO sample. The results indicate that the addition of $\mathrm{SO}$ into the reaction solution does not change the crystalline of the coating. High-resolution spectra of $\mathrm{O} 1 \mathrm{~s}$ and $\mathrm{Al} 2 \mathrm{p}$ of the $\mathrm{LDH}$ and LDH/SO samples are shown in Fig. 3a-d. O 1s peak of both samples can be divided into two peaks centered at 530.9 and $531.9 \mathrm{eV}$ corresponding to oxygen peak in hydroxyl bonding with $\mathrm{Mg}$ and $\mathrm{Al}$. $\mathrm{Al} 2 \mathrm{p}$ peak of the $\mathrm{LDH}$ and $\mathrm{LDH} / \mathrm{SO}$ samples centered at $74.2 \mathrm{eV}$ is ascribed to aluminum peak bonding with hydroxyl. The results of XPS further confirm the existence of $\mathrm{Mg}-\mathrm{Al}$ $\mathrm{LDH}$ on the treated samples. Fig. 3e shows the FTIR spectra. For the LDH and LDH/SO samples, the broad band at $3442 \mathrm{~cm}^{-1}$ is ascribed to the vibrations of $\mathrm{OH}^{-}$of either the water molecules or hydroxyl groups in the brucite-like layers [22,23], while the peak at $1635 \mathrm{~cm}^{-1}$ is associated with the absorbed water in the interlayer of $\mathrm{Mg}$-Al LDH structure [24]. The peaks at $2922 \mathrm{~cm}^{-1}$ and $2852 \mathrm{~cm}^{-1}$ are only detected in the spectra of SO powder and LDH/SO sample, attributed to the asymmetric and symmetric $\mathrm{C}-\mathrm{H}$ stretching vibration of the alkyl group of oleate groups, further indicating that oleate groups are successfully anchored on the surface of LDH/SO sample. The cross-sectional morphology of $\mathrm{LDH}$ and $\mathrm{LDH} / \mathrm{SO}$ are presented in Fig. 4. The thickness of LDH and LDH/SO samples are $3.67 \pm 0.37 \mu \mathrm{m}$ and $1.93 \pm 0.12 \mu \mathrm{m}$, respectively, and the results are confirmed by the corresponding scanning maps. It is worth noting that no $\mathrm{C}$ element was detected on the cross sectional surface of LDH/SO sam- 
a
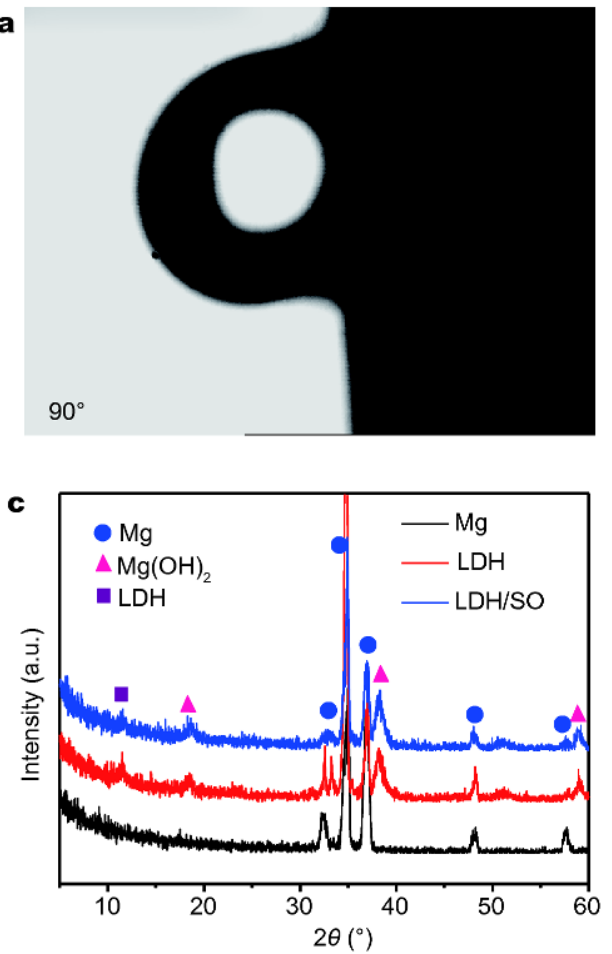

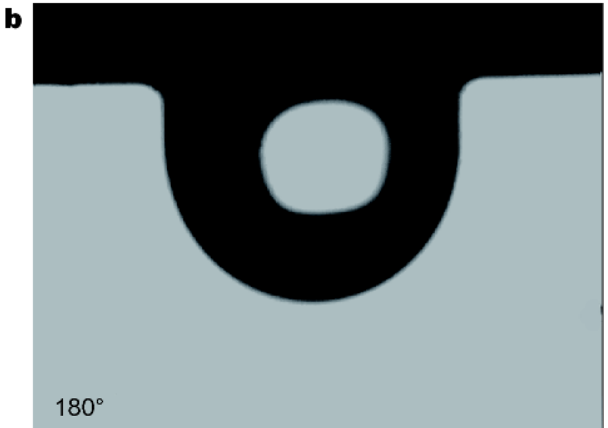

d 5

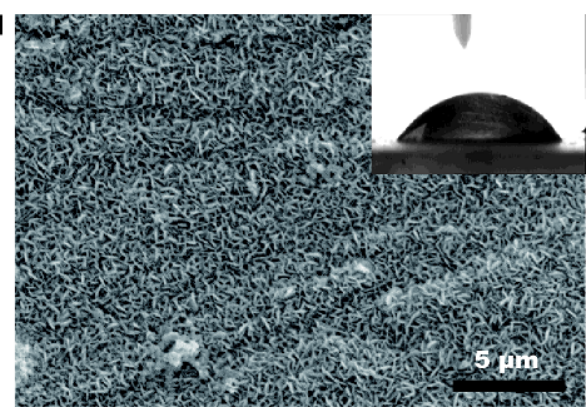

Figure 2 Shapes of water droplets on the surface of the LDH/SO sample with different tilt angles: $90^{\circ}$ (a) and $180^{\circ}$ (b). (c) XRD patterns of the Mg, $\mathrm{LDH}$ and LDH/SO samples. (d) SEM image and (inset) water angle of the LDH sample.
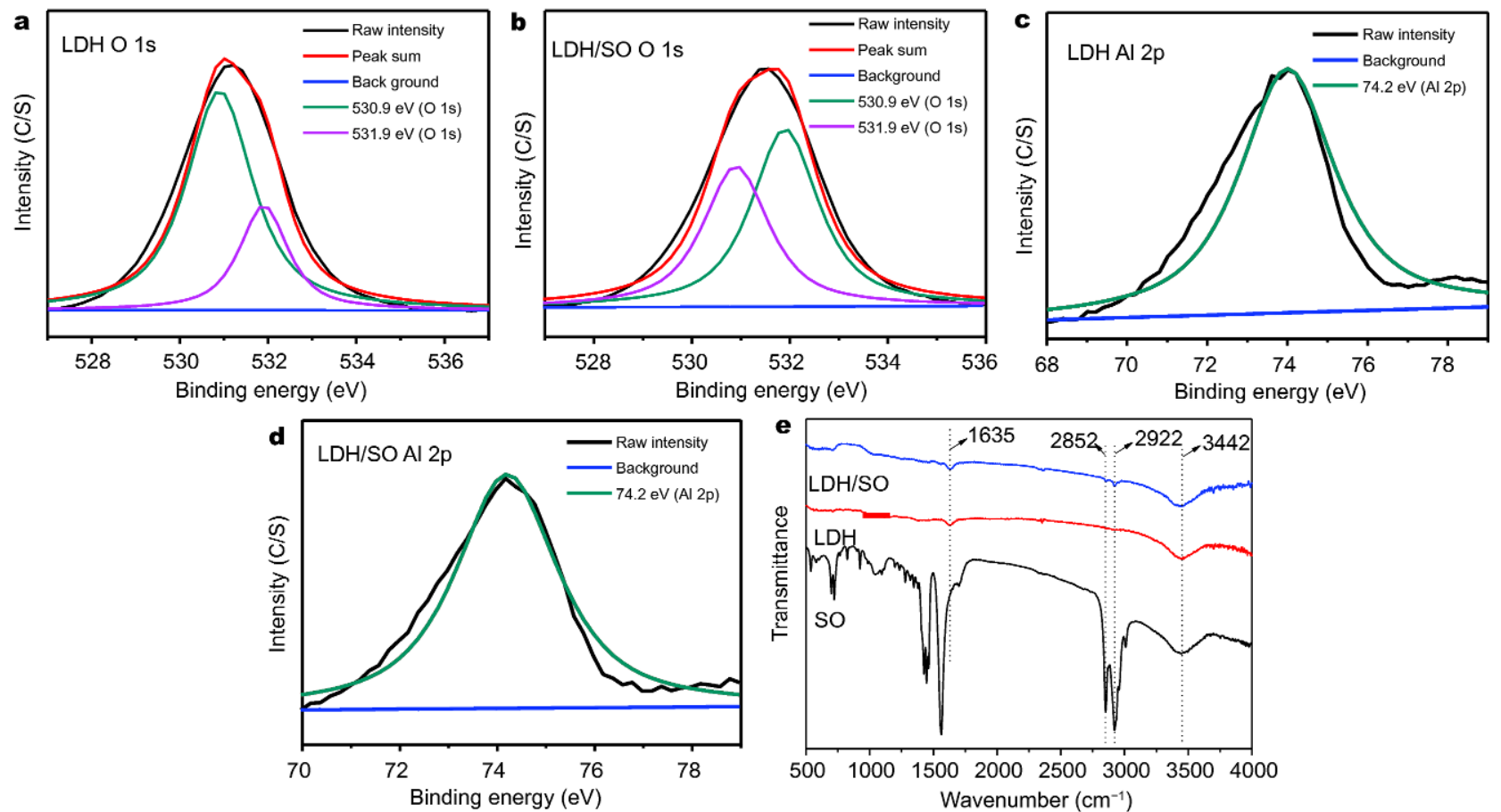

Figure 3 High-resolution spectra of O 1s of LDH (a) and LDH/SO (b), Al 2p of LDH (c) and LDH/SO (d). (e) FTIR spectra of SO, LDH and LDH/SO samples. 

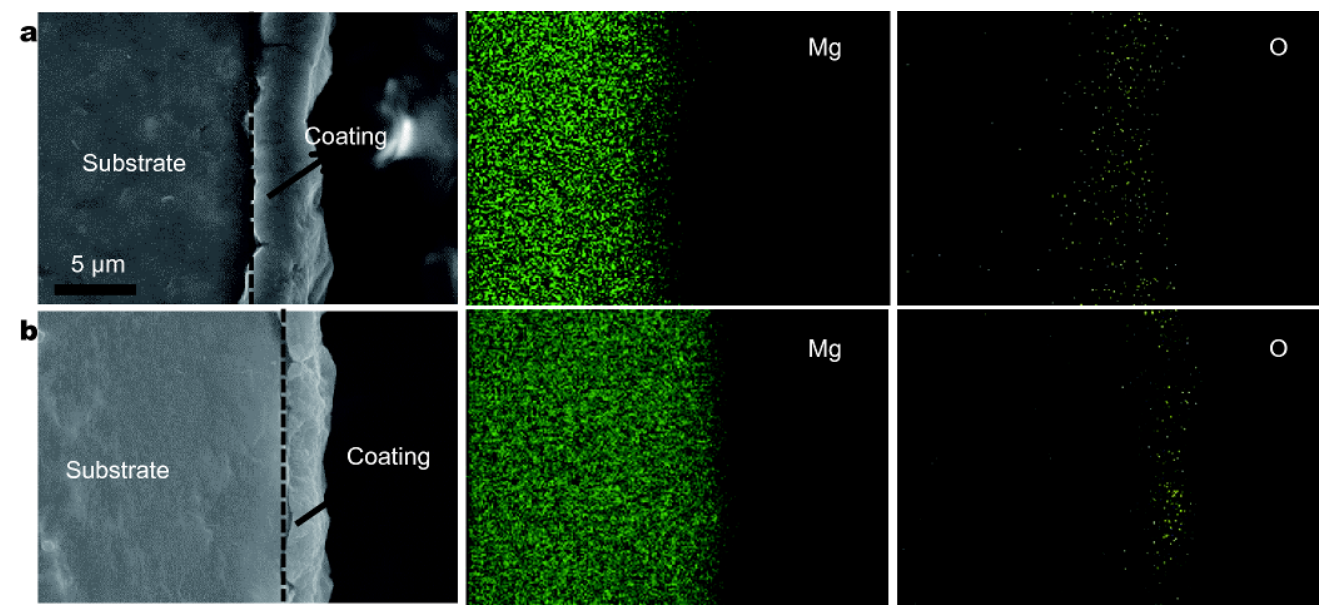

Figure 4 Cross-sectional morphology and scanning maps of Mg and $\mathrm{O}$ of LDH (a) and LDH/SO (b).

ple, demonstrating that oleate groups only exist on the outermost surface.

Without adding SO into the reaction solution, the asobtained LDH sample shows intrinsic hydrophilicity (Fig. $2 \mathrm{~d}$ ). After adding $\mathrm{SO}$, the as-obtained $\mathrm{LDH} / \mathrm{SO}$ sample shows superhydrophobicity with highly adhesive force (Figs $1 \mathrm{c}$ and $2 \mathrm{a}, \mathrm{b}$ ). It is widely accepted that a rough surface morphology and a low surface energy would lead to a superhydrophobic surface $[25,26]$. Considering that surface morphology (Figs $1 \mathrm{c}$ and $2 \mathrm{~d}$ ) and crystalline phase compositions (Fig. 2c) of $\mathrm{LDH}$ and $\mathrm{LDO} / \mathrm{SO}$ samples are similar, it can be concluded that it is the oleate groups on the surface of LDH/SO sample result in its superhydrophobicity. During the process of hydrothermal treatment, oleate groups adhere to the surface of the $\mathrm{LDH} / \mathrm{SO}$ coating via two ways as depicted in Fig. 5a. A spot of oleate groups bind on the crystal of $\mathrm{Mg}(\mathrm{OH})_{2}$ via the van der Waals force and hydrogen bond [27]. At the same time, the electrostatic attraction between the positive metal hydroxide layer of $\mathrm{Mg}-\mathrm{Al} \mathrm{LDH}$ and the negative oleate groups would result in a large number of oleate groups binding on the surface of LDH/SO sample [16,28]. In order to verify this deduction, pure $\mathrm{Mg}(\mathrm{OH})_{2}$ coating and $\mathrm{Mg}(\mathrm{OH})_{2} / \mathrm{SO}$ coating were fabricated on pure $\mathrm{Mg}$ (Fig. S1). In the absence of Mg-Al LDH phase, the $\mathrm{C}$ content of $\mathrm{Mg}(\mathrm{OH})_{2} / \mathrm{SO}$ sample $(6.22 \pm 0.51 \%)$ was much less than $\mathrm{LDH} / \mathrm{SO}(23.43 \pm 0.86 \%)$ (Table S1 and Table 1 ), indicating less oleate groups binding on $\mathrm{Mg}(\mathrm{OH})_{2} / \mathrm{SO}$. As a consequence, the $\mathrm{CA}$ of $\mathrm{Mg}(\mathrm{OH})_{2} / \mathrm{SO}$ was only $70.3 \pm$ $9.5^{\circ}$, far lower than that of LDH/SO $\left(151.2 \pm 2.4^{\circ}\right)$.

Fig. 5b, c illustrate the status of the drop water in contact with the LDH or LDH/SO samples. For LDH, though its surface is rough, hydroxyls on its surface leads

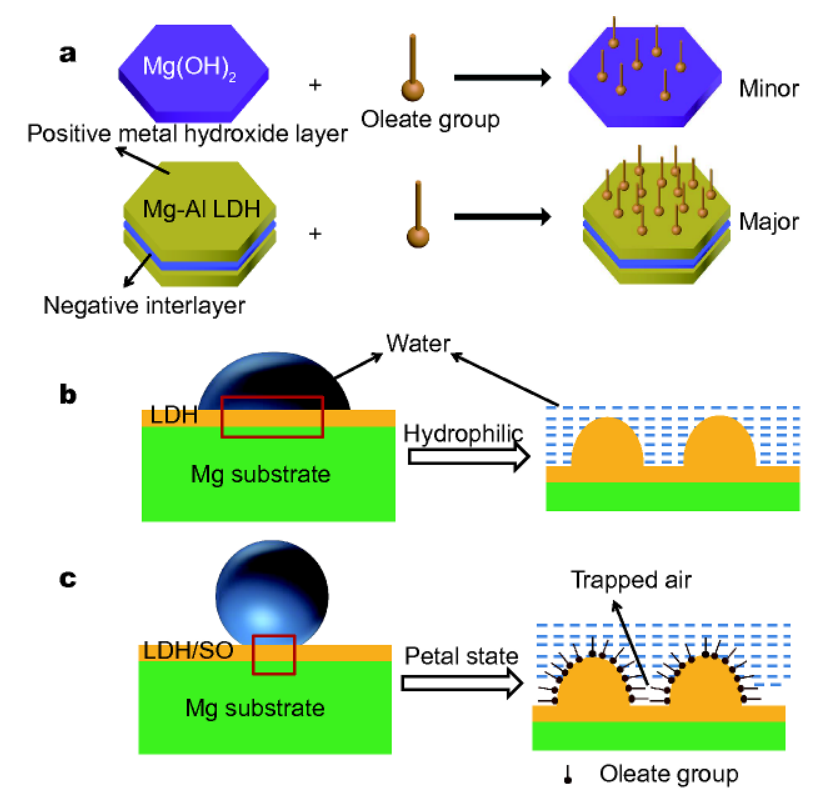

Figure 5 (a) Schematic illustration of oleate groups bound on $\mathrm{Mg}(\mathrm{OH})_{2}$ and Mg-Al LDH. (b, c) Schematic illustration of water in contact with the surface of $\mathrm{LDH}$ and $\mathrm{LDH} / \mathrm{SO}$ samples.

to its hydrophility (Fig. 5a). Different with Cassie's state (a classic model for lotus effect, Fig. S2), LDH/SO sample shows highly adhesive force, and thus a petal effect model (Cassie impregnating wetting state) is used (Fig. 5b) [6]. The nanoflake-like surface combines with hydrophobic long-chain aliphatic groups of oleate are responsible for its superhydrophobicity [16]. The highly adhesive property results from the cooperation effect between the negative pressures induced by the volume change of sealed air pockets and the van der Waals' attraction at the solidliquid interface $[7,11]$. 


\section{Chemical stability and mechanical stability}

As shown in Fig. 6a, though the $\mathrm{pH}$ value varies from 4 to 12 , the CAs of water on the LDH/SO sample are stable (around $150^{\circ}$ ). When the $\mathrm{pH}$ value is lower than 4 , the CA sharply decreases, which was resulted from the collapse of $\mathrm{Mg}(\mathrm{OH})_{2}$ and $\mathrm{Mg}-\mathrm{Al} \mathrm{LDH}$ phases in a strongly acidic environment [29]. The $\mathrm{CA}$ also slightly decreases at $\mathrm{pH}$ 13 , owing to that the bond between oleate groups and $\mathrm{Mg}-\mathrm{Al} \mathrm{LDH}$ layer would be destroyed in an environment rich with $\mathrm{Na}^{+}$, and then some oleate groups would bond with $\mathrm{Na}^{+}$. The reaction equations are described as follows $[30,31]$ :

$\mathrm{C}_{17} \mathrm{H}_{33} \mathrm{COO}-\mathrm{LDH}$ (positive layer) $\rightarrow \mathrm{C}_{17} \mathrm{H}_{33} \mathrm{COO}^{-}+\mathrm{LDH}^{+}$

$\mathrm{C}_{17} \mathrm{H}_{33} \mathrm{COO}^{-}+\mathrm{Na}^{+} \rightarrow \mathrm{C}_{17} \mathrm{H}_{33} \mathrm{COONa}$

$\mathrm{LDH}^{+}+\mathrm{OH}^{-} \rightarrow \mathrm{LDH}-\mathrm{OH}$

These results indicate that the $\mathrm{LDH} / \mathrm{SO}$ sample can bear a moderate environment. Since the $\mathrm{pH}$ value of human body is around 7.4 [32], the as-prepared surface should show superhydrophobic in human body.

Implant, especially orthopedic implant, is unavoidable to rub with the surrounding tissue. Considering that, an abrasion test was used to characterize the samples' mechanical stability, as displayed in Fig. 6b. After moving $500 \mathrm{~mm}$ on a 1000\# SiC abrasive paper in one direction under a pressure of $2.45 \mathrm{kPa}$, the CA of the sample was still higher than $140^{\circ}$. During the moving process, the oleate groups in the connected section between the sample and the abrasive paper were destructed, while profiting from its nanoflake like structure, most regions were not connected with the abrasive paper. On the other hand, the SiC powder adhering on the LDHO/SO sample' surface was also disadvantage for its superhydrophobicity. As a consequence, the CA was slightly decreased after abrasion. Nevertheless, the LDH/SO sample shows good mechanical durability to some extent.

\section{Corrosion resistance performance}

For the clinical application of $\mathrm{Mg}$, the first problem needs to be solved is its poor corrosion resistance. The polarization curves are presented in Fig. $7 \mathrm{a}$ and corresponding corrosion parameters are shown in Table 2. Compared with $\mathrm{Mg}$, both the LDH and LDH/SO samples show significant lower free current density $i_{\text {corr }}$ and higher corrosion potential $E_{\text {corr }}$ especially for the $\mathrm{LDH} / \mathrm{SO}$ sample. In addition, the polarization resistance $R_{\mathrm{p}}$ of $\mathrm{LDH}$ sample is slightly higher than that of $\mathrm{Mg}$, while $R_{\mathrm{p}}$ of the $\mathrm{LDH} / \mathrm{SO}$ sample is about twenty times higher than that of $\mathrm{Mg}$ and LDH sample. It can be easily concluded that LDH/SO coating shows the best corrosion resistance. This result comes from the joint effect of the sealed air, which would
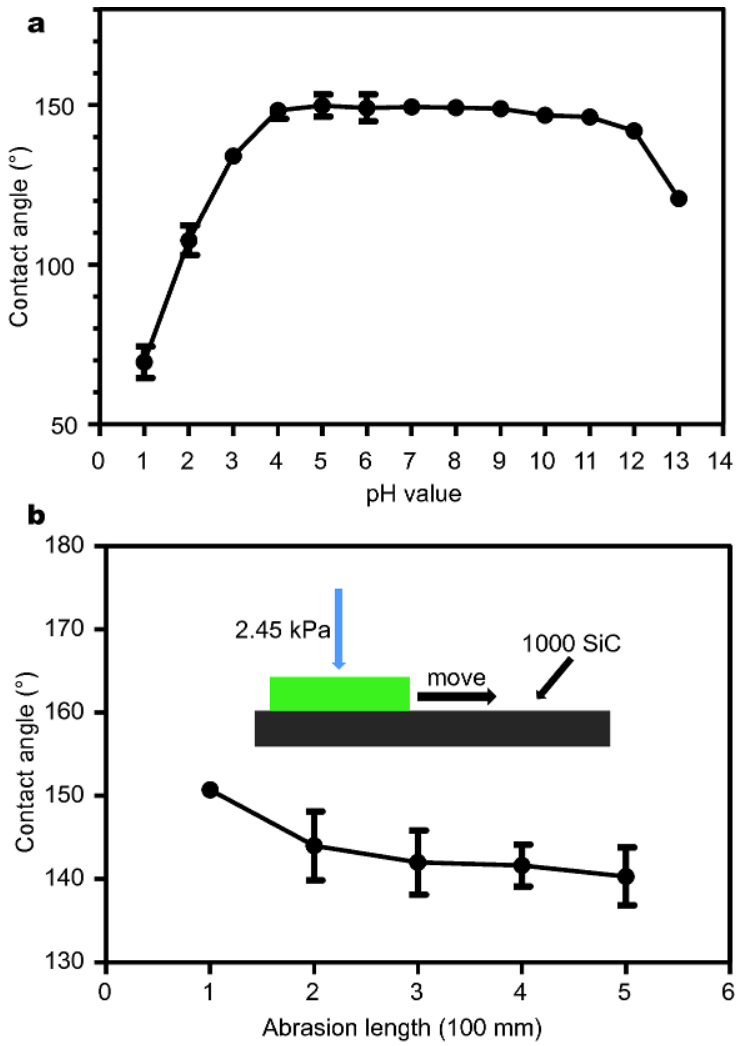

Figure 6 (a) $\mathrm{CA}$ of the LDH/SO sample as a function of $\mathrm{pH}$. (b) Schematic illustration of the abrasion test and CA of the LDH/SO sample as a function of abrasion length (mean $\pm \mathrm{SD}, N=3$ ).

reduce the corrosion area, and the oleate groups on its surface, which would inhibit the transportation of electrons.

EIS was also used to evaluate the protective ability of $\mathrm{LDH}$ and $\mathrm{LDH} / \mathrm{SO}$ coating, and the results are shown in Fig. $7 b, c$. The LDH/SO sample exhibits remarkably larger overall impedance in the entire scanned frequency range than the other two samples. The equivalent electrical circuit model of these samples can be described as $R_{\mathrm{s}}\left(Q_{\mathrm{f}}\right.$ $\left.\left(R_{\mathrm{f}}\left(Q_{\mathrm{dl}} R_{\mathrm{ct}}\right)\right)\right)$, as drawn in Fig. $7 \mathrm{~d}[5,33] . R_{\mathrm{s}}$ represents the solution resistance. $Q_{\mathrm{f}}$ and $R_{\mathrm{f}}$ are the capacitance and resistance of the corrosion production or coating on $\mathrm{Mg}$, respectively. $R_{\mathrm{ct}}$ and $Q_{\mathrm{dl}}$ are the charge transfer resistance and the constant phase element of the electrical double layer, respectively. The fitting results are listed in Table 2. It is noteworthy that $R_{\mathrm{ct}}$ directly refers to the impedance of the corrosion reaction. The $R_{\mathrm{ct}}$ value of LDH/SO is two times and five times larger than that of $\mathrm{LDH}$ and $\mathrm{Mg}$, respectively, indicating the favorable corrosion resistance of LDH/SO coating, which is consistent with the result of polarization curves.

The results of long-term corrosion resistance are dis- 

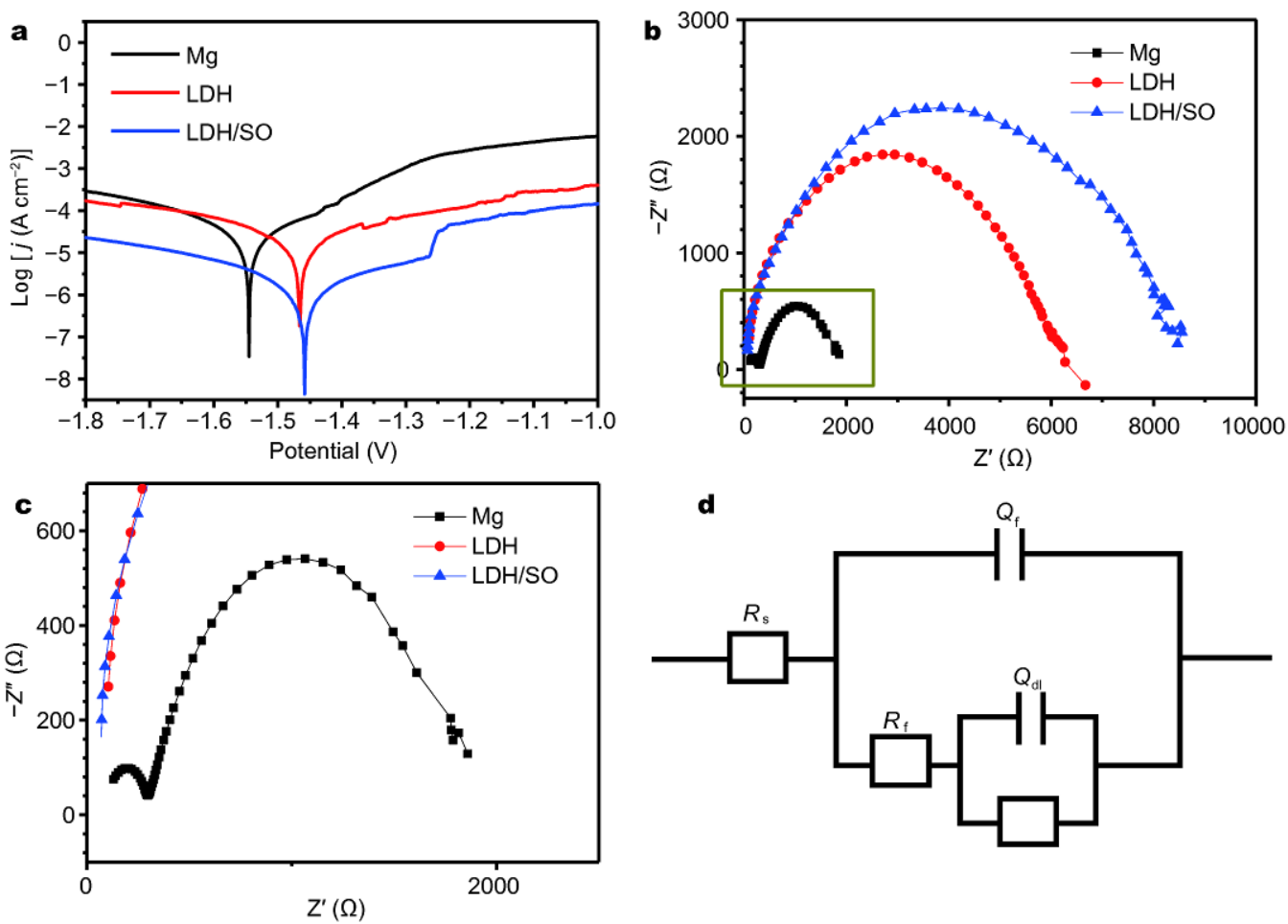

Figure 7 (a) Potentiodynamic polarization curves of $\mathrm{Mg}, \mathrm{LDH}$ and $\mathrm{LDH} / \mathrm{SO}$ samples in PBS at $37^{\circ} \mathrm{C}$. (b) EIS results of $\mathrm{Mg}, \mathrm{LDH}$ and $\mathrm{LDH} / \mathrm{SO}$ samples in PBS at $37^{\circ} \mathrm{C}$; the magnification of the block in (b) shown in (c). (d) Equivalent circuit of EIS fitting for Mg, LDH and LDH/SO samples.

Table 2 Free corrosion potential $\left(E_{\text {corr }}\right)$, corrosion current densities $\left(i_{\text {corr }}\right)$, polarization resistance $\left(R_{\mathrm{p}}\right)$ calculated according to the polarization curves and fitted results of EIS spectra of $\mathrm{Mg}, \mathrm{LDH}$ and $\mathrm{LDH} / \mathrm{SO}$ samples

\begin{tabular}{|c|c|c|c|c|c|c|c|c|}
\hline \multirow{2}{*}{ Samples } & \multicolumn{3}{|c|}{ Polarization curves } & \multicolumn{5}{|c|}{ Nyquist EIS spectra } \\
\hline & $j_{\text {corr }}\left(\mu \mathrm{A} \mathrm{cm}^{-2}\right)$ & $E_{\text {corr }}(\mathrm{V})$ & $R_{\mathrm{p}}\left(\mathrm{k} \Omega \mathrm{cm}^{-2}\right)$ & $R_{\mathrm{s}}\left(\Omega \mathrm{cm}^{2}\right)$ & $Q_{\mathrm{f}}\left(\mu \mathrm{F} \mathrm{cm}{ }^{-2}\right)$ & $R_{\mathrm{f}}\left(\Omega \mathrm{cm}^{2}\right)$ & $Q_{\mathrm{dl}}\left(\mu \mathrm{F} \mathrm{cm}^{-2}\right)$ & $R_{\mathrm{ct}}\left(\Omega \mathrm{cm}^{2}\right)$ \\
\hline $\mathrm{Mg}$ & 22.2 & -1.54 & 58 & 23.8 & 0.094 & 51.5 & 76.8 & 415.8 \\
\hline $\mathrm{LDH}$ & 14.4 & -1.47 & 79.8 & 18.36 & 0.026 & 541.7 & 4.05 & 1021 \\
\hline $\mathrm{LDH} / \mathrm{SO}$ & 0.98 & -1.45 & 1160 & 12.1 & 0.034 & 338.3 & 9.47 & 2004 \\
\hline
\end{tabular}

played in Fig. 8. The average mass loss of LDH/SO sample is $21.4 \mathrm{mg}$ (Fig. 8b), which is substantially lower than that of the $\mathrm{LDH}$ sample $(26 \mathrm{mg}$ ) and $\mathrm{Mg}$ (123.3 mg), suggesting its best long-term corrosion resistance. The result is further confirmed by the corrosion morphology of the samples (Fig. 8a).

The above results demonstrate that, whether from the point of electrochemical test or directly observation of the degradation behavior, the LDH/SO sample with a superhydrophobic surface, shows superior protective effect.

\section{Cytocompatibility}

Faster migration of endothelial cells (ECs) would stimulate faster wound healing after injury or stent implantation [34]. Scarification method is a conventional means to evaluate cell migration [35]. Here, the extraction was used to evaluate the migration of HUVECs. As shown in Fig. 9a, only a handful of cells in $\mathrm{Mg}$ extraction migrated into the line. After coated with LDH, cell migration was significantly enhanced. It should be noted that cells in the $\mathrm{LDH} / \mathrm{SO}$ extraction almost migrated across the line, indicating the fastest migration rate. The quantitative results of cell migration are expressed in Fig. 9b, which further confirms the qualitative results (Fig. 9a). Compared with the $\mathrm{Mg}$ and $\mathrm{LDH}$ samples, the $\mathrm{LDH} / \mathrm{SO}$ sample shows the best corrosion resistance, and thus $\mathrm{pH}$ value and $\mathrm{Mg}^{2+}$ of its extraction are changed least, leading to the fastest migration rate.

For cytotoxicity evaluation, the extraction was used to evaluate the cell viability, and the results are displayed in Fig. 9c. Before diluted, both extraction of the $\mathrm{Mg}$ and LDH samples show obviously cytotoxicity, whose cell 
a
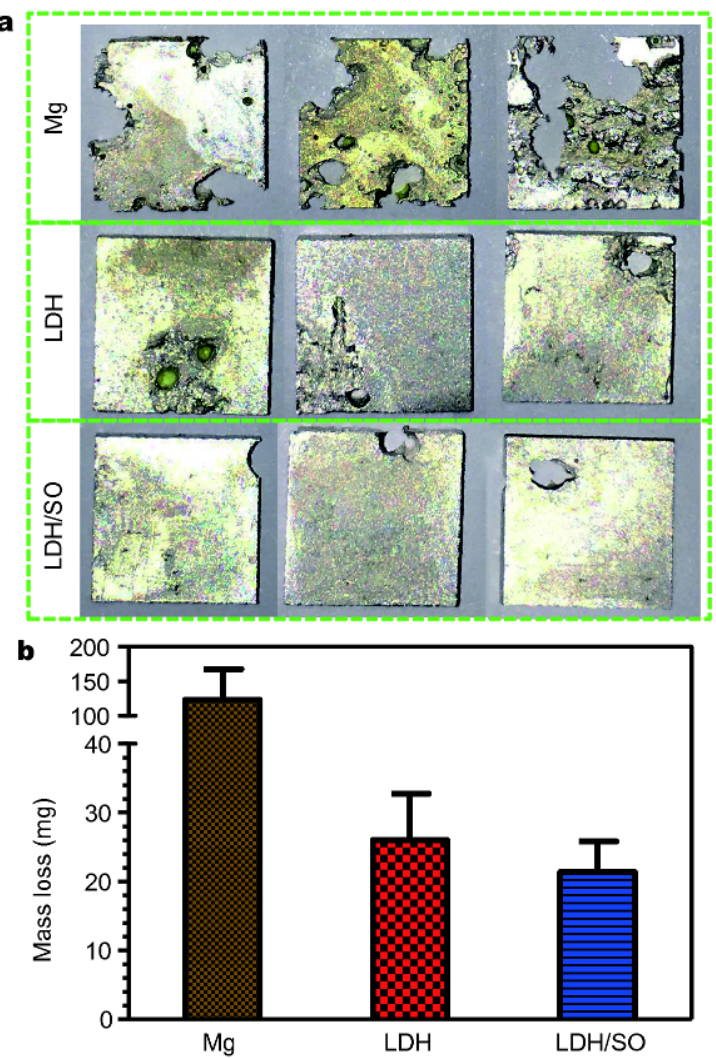

Figure 8 (a) Corrosion morphology and (b) mass loss of Mg, LDH and $\mathrm{LDH} / \mathrm{SO}$ samples after immersion in PBS for 30 days (mean $\pm \mathrm{SD}, N=$ 3). viability are $19.6 \%$ and $64.3 \%$, respectively. Compared with the $\mathrm{Mg}$ and $\mathrm{LDH}$ extractions, the cell viability of LDH/SO extraction was significantly higher (84.7\%). After diluted to $60 \%$, the extraction of $\mathrm{LDH}$ and LDH/SO samples showed no cytotoxicity. Further diluted to 30\%, the cell viability in $\mathrm{Mg}$ extraction sharply increased and cell proliferation was promoted. With the dilution of extractions, the $\mathrm{pH}$ value and $\mathrm{Mg}^{2+}$ concentration decreased, leading to a more suitable environment for cell proliferation. Whether diluted or not, the LDH/SO extraction showed little cytotoxicity, suggesting its excellent cytocompatibility.

Cell adhesion and spreading are critical steps for cell survival and then proliferation on substrates. Fig. 10 shows the initial cell adhesion process of HUVECs seeded on the samples. After cultured for $1 \mathrm{~h}$, the expression of filamentous F-actin for cells on the $\mathrm{LDH}$ and $\mathrm{LDH} / \mathrm{SO}$ samples was better than that on the $\mathrm{Mg}$ sample. After cultured for $4 \mathrm{~h}$, the cells on the $\mathrm{Mg}$ sample remained their round morphology, while cells on the LDH and LDH/SO samples showed polygon shape. SEM morphology confirms the phenomenon (Fig. S3). After $24 \mathrm{~h}$ of incubation, few cells were detected on the $\mathrm{Mg}$ sample. Cells on the LDH/SO sample displayed the same spreading degree with that on the LDH sample, and there were more cells adhered on the surface of LDH/SO sample. These results indicate that superhydrophobic
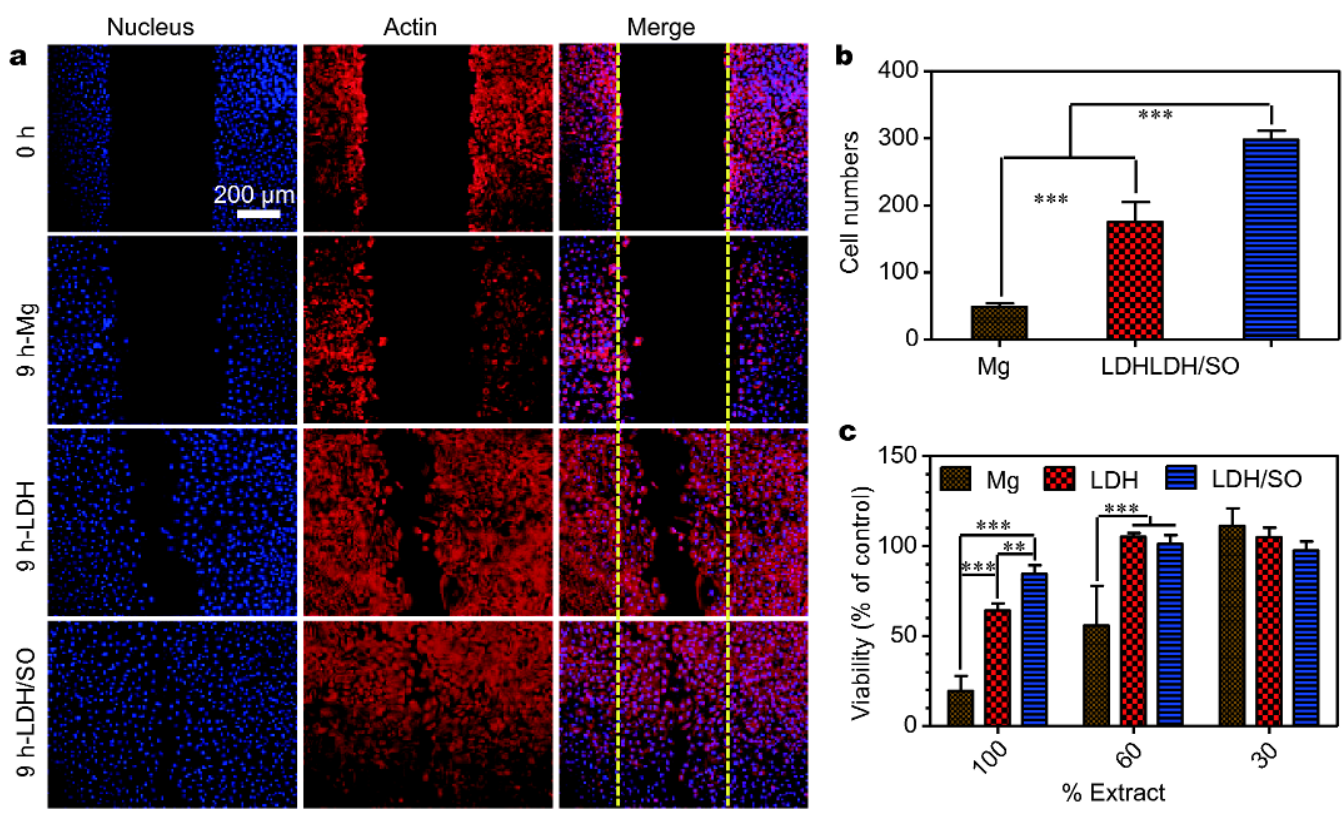

Figure 9 (a) Migration of HUVECs after incubation $9 \mathrm{~h}$ in extractions of Mg, LDH and LDH/SO samples (the scratch area is between the two yellow dotted lines) and (b) numbers of cells migrating into the blank area (mean $\pm \mathrm{SD}, N=3$ ). (c) Viability of HUVECs after incubation for 1 day in different concentrations of extractions of $\mathrm{Mg}, \mathrm{LDH}$ and $\mathrm{LDH} / \mathrm{SO}$ samples. 

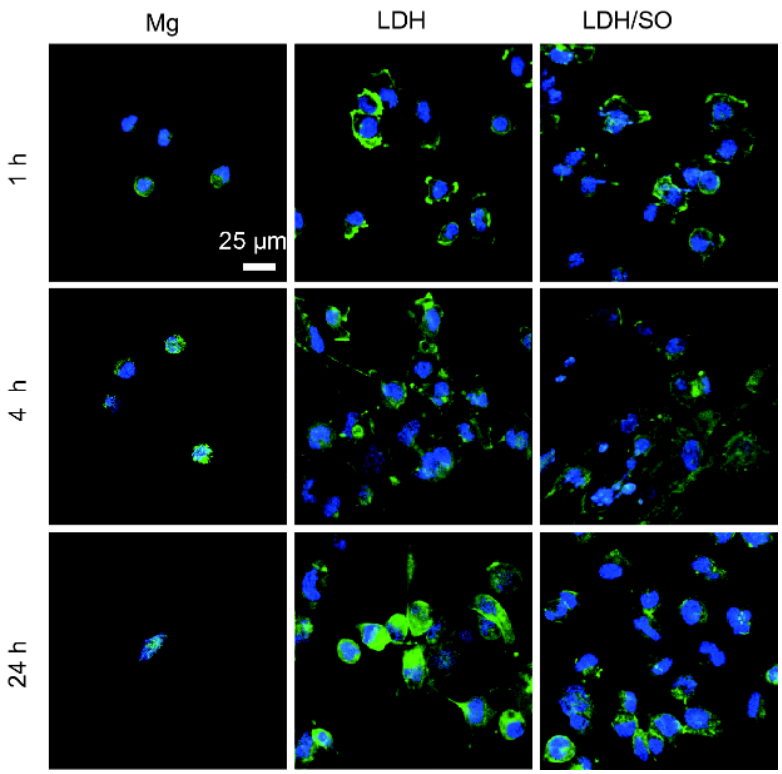

Figure 10 Cell adhesion of HUVECs after cultured on $\mathrm{Mg}, \mathrm{LDH}$ and $\mathrm{LDH} / \mathrm{SO}$ samples for 1,4 and $24 \mathrm{~h}$, actin stained with FITC (green) and nucleus stained with DAPI. surface of the LDH/SO sample would not influence the cells' adhesion and spreading process. The superhydrophobic surface based on lotus effect (Fig. S2) has a small solid-liquid contact area, resulting in the inhibition of cell adhesion. In contrast, the as-prepared superhydrophobic in this work is based on petal effect (Fig. 5c) with an impregnating wetting state. As a consequence, the solid-liquid contact area is greatly increased and cells on such superhydrophobic surface (the LDH/SO sample) can adhere and spread as on hydrophilic surface (the LDH sample). Furthermore, the better corrosion resistance of the LDH/SO sample leads to a milder environment for cell proliferation (Fig. S4).

\section{Hemocompatibility}

Since hemocompatibility is a vital evaluation for bloodcontacting materials, platelet adhesion assay and HR assay were conducted in this work. The adherent platelets on the $\mathrm{Mg}, \mathrm{LDH}$ and $\mathrm{LDH} / \mathrm{SO}$ samples are shown in Fig. 11a-f. As the Mg sample is severely corroded (Fig. 11a,d), it is hard to distinguish platelets from the corrosion
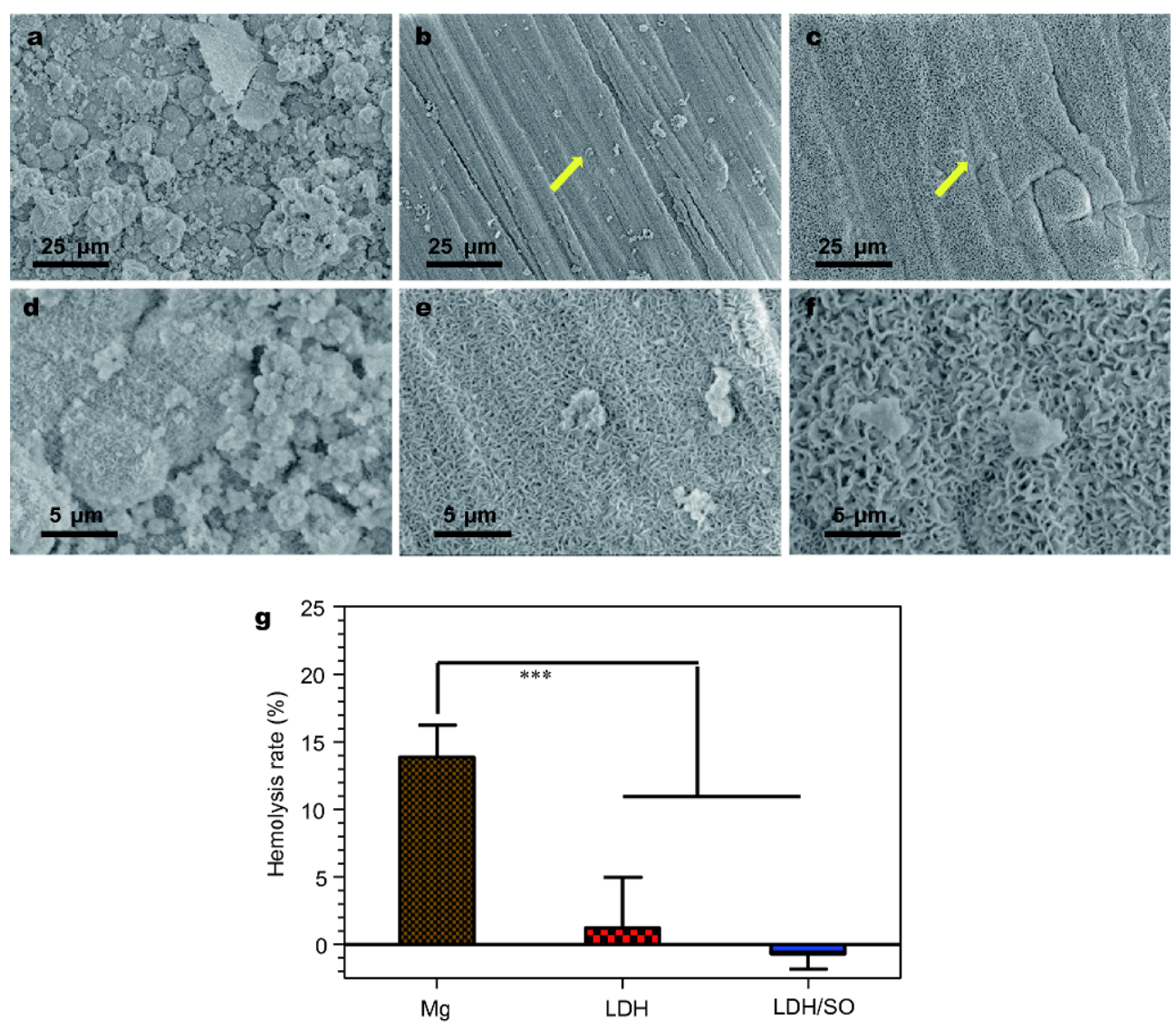

Figure 11 (a-f) SEM images of platelets adhered on the surface of $\mathrm{Mg}(\mathrm{a}, \mathrm{d}), \mathrm{LDH}(\mathrm{b}, \mathrm{e})$ and LDH/SO (c, f) samples. (g) Hemolysis rate of Mg, LDH and $\mathrm{LDH} / \mathrm{SO}$ samples (mean $\pm \mathrm{SD}, N=4$ ). 
products. After modified with LDH coating, the corrosion resistance of the sample was greatly enhanced (Fig. 7), and there are many platelets on its surface (Fig. 11b, e). The shape of the platelets is not round, indicating that the adhered platelets are damaged. Further fabricating a superhydrophobic surface, the amount of adherent platelets was significantly decreased (Fig. 11c, f). The results reveal that the LDH/SO sample with a superhydrophobic surface could effectively inhibit the adhesion of platelets, indicating a promising anticoagulation effect. The different sizes of HUVECs and platelets might play roles in their different adhesion activities. The HR value represents the degree of erythrocyte destruction. As shown in Fig. 11g, pure $\mathrm{Mg}$ shows a high HR value $(13.9 \%)$ caused by its rapid degradation. The LDH sample presents a much lower HR value (1.2\%), which is within the safe value of $5 \%$. Compared with the LDH sample, the corrosion resistance of $\mathrm{LDH} / \mathrm{SO}$ sample is further enhanced, resulting in an even lower HR value. The results of platelet adhesion and $\mathrm{HR}$ value suggest that $\mathrm{LDH} / \mathrm{SO}$ sample coating is suitable for blood-contacting biomaterials.

\section{CONCLUSIONS}

Inspired by the petal effect, a superhydrophobic and highly adhesive coating was successfully fabricated on the surface of Mg via a simple one-step method. The superhydrophobic property of the coating was determined by the SO concentration of the reaction solution, and was independent of the reaction time. The oleate groups on the surface of LDH/SO sample were mainly bound with the positive layer of $\mathrm{Mg}$ - $\mathrm{Al} \mathrm{LDH}$ via electrostatic attraction. The as-prepared LDH/SO coating could effectively improve the corrosion resistance of the substrate. With better corrosion resistance, cell migration and viability in the extraction of LDH/SO sample were greatly enhanced. Furthermore, owing to its impregnating wetting state, cells directly cultured on its surface showed the same degree of adhesion and spreading with hydrophilic surface. Finally, the platelet adhesion was effectively inhibited and the hemolysis ratio was reduced to a level for clinical application. With favorable corrosion resistance, cytocompatibility and hemocompatibility, the LDH/SO coating in the present study shows a promising application in clinic.

Received 13 June 2017; accepted 2 August 2017; published online 30 August 2017

1 Gu XN, Li SS, Li XM, et al. Magnesium based degradable biomaterials: a review. Front Mater Sci, 2014, 8: 200-218

2 Zhao D, Witte F, Lu F, et al. Current status on clinical applications of magnesium-based orthopaedic implants: a review from clinical translational perspective. Biomaterials, 2017, 112: 287-302

3 Tian P, Liu X, Ding C. In vitro degradation behavior and cytocompatibility of biodegradable AZ31 alloy with PEO/HT composite coating. Colloids Surfs B-Biointerfaces, 2015, 128: 44-54

4 Tomozawa M, Hiromoto S. Microstructure of hydroxyapatite- and octacalcium phosphate-coatings formed on magnesium by a hydrothermal treatment at various $\mathrm{pH}$ values. Acta Mater, 2011, 59: 355-363

5 Wei $\mathrm{Z}$, Tian $\mathrm{P}$, Liu $\mathrm{X}$, et al. In vitro degradation, hemolysis, and cytocompatibility of PEO/PLLA composite coating on biodegradable AZ31 alloy. J Biomed Mater Res, 2015, 103: 342-354

6 Feng L, Zhang Y, Xi J, et al. Petal effect: a superhydrophobic state with high adhesive force. Langmuir, 2008, 24: 4114-4119

7 Hong X, Gao X, Jiang L. Application of superhydrophobic surface with high adhesive force in no lost transport of superparamagnetic microdroplet. J Am Chem Soc, 2007, 129: 1478-1479

8 Jin M, Feng X, Feng L, et al. Superhydrophobic aligned polystyrene nanotube films with high adhesive force. Adv Mater, 2005, 17: 1977-1981

9 Wang S, Liu K, Yao X, et al. Bioinspired surfaces with superwettability: new insight on theory, design, and applications. Chem Rev, 2015, 115: 8230-8293

10 Liu M, Jiang L. Switchable adhesion on liquid/solid interfaces. Adv Funct Mater, 2010, 20: 3753-3764

11 Hu Z, Zhang X, Liu Z, et al. Regulating water adhesion on superhydrophobic $\mathrm{TiO}_{2}$ nanotube arrays. Adv Funct Mater, 2014, 24: 6381-6388

12 Peng F, Li H, Wang D, et al. Enhanced corrosion resistance and biocompatibility of magnesium alloy by $\mathrm{Mg}$-Al-layered double hydroxide. ACS Appl Mater Interfaces, 2016, 8: 35033-35044

13 Wang Q, O'Hare D. Recent advances in the synthesis and application of layered double hydroxide (LDH) nanosheets. Chem Rev, 2012, 112: 4124-4155

14 Delhoyo C. Layered double hydroxides and human health: an overview. Appl Clay Sci, 2007, 36: 103-121

15 Hosni K, Abdelkarim O, Frini-Srasra N, et al. Synthesis, structure and photocatalytic activity of calcined Mg-Al-Ti-layered double hydroxides. Korean J Chem Eng, 2015, 32: 104-112

16 Chen FF, Zhu YJ, Xiong ZC, et al. Highly flexible superhydrophobic and fire-resistant layered inorganic paper. ACS Appl Mater Interfaces, 2016, 8: 34715-34724

17 Li J, Wang G, Wang D, et al. Alkali-treated titanium selectively regulating biological behaviors of bacteria, cancer cells and mesenchymal stem cells. J Colloid Interface Sci, 2014, 436: 160-170

18 Wang D, Ge N, Li J, et al. Selective tumor cell inhibition effect of $\mathrm{Ni}-\mathrm{Ti}$ layered double hydroxides thin films driven by the reversed $\mathrm{pH}$ gradients of tumor cells. ACS Appl Mater Interfaces, 2015, 7: $7843-7854$

19 Jeong H, Yoo Y. Synthesis and characterization of thin films on magnesium alloy using a hydrothermal method. Surf Coatings Tech, 2015, 284: 26-30

20 Lin JK, Uan JY, Wu CP, et al. Direct growth of oriented $\mathrm{Mg}-\mathrm{Fe}$ layered double hydroxide ( $\mathrm{LDH}$ ) on pure $\mathrm{Mg}$ substrates and in vitro corrosion and cell adhesion testing of $\mathrm{LDH}$-coated $\mathrm{Mg}$ samples. J Mater Chem, 2011, 21: 5011

21 Ishizaki T, Cho SP, Saito N. Morphological control of vertically self-aligned nanosheets formed on magnesium alloy by surfactantfree hydrothermal synthesis. CrystEngComm, 2009, 11: 2338

22 Kameda T, Saito M, Umetsu Y. Preparation and characterisation of $\mathrm{Mg}$-Al layered double hydroxides intercalated with 2-naphthalene 
sulphonate and 2,6-naphthalene disulphonate. Mater Trans, 2006, 47: 923-930

23 Kamiyama N, Panomsuwan G, Yamamoto E, et al. Effect of treatment time in the $\mathrm{Mg}(\mathrm{OH})_{2} / \mathrm{Mg}-\mathrm{Al} \mathrm{LDH}$ composite film formed on $\mathrm{Mg}$ alloy AZ31 by steam coating on the corrosion resistance. Surf Coatings Tech, 2016, 286: 172-177

24 Jevtic M, Mitric M, Skapin S, et al. Crystal structure of hydroxyapatite nanorods synthesized by sonochemical homogeneous precipitation. Cryst Growth Des, 2008, 8: 2217-2222

Wang Z, Li Q, She Z, et al. Low-cost and large-scale fabrication method for an environmentally-friendly superhydrophobic coating on magnesium alloy. J Mater Chem, 2012, 22: 4097

26 Wang Z, Su Y, Li Q, et al. Researching a highly anti-corrosion superhydrophobic film fabricated on AZ91D magnesium alloy and its anti-bacteria adhesion effect. Mater Charact, 2015, 99: 200-209 Liang Y, Hilal N, Langston $\mathrm{P}$, et al. Interaction forces between colloidal particles in liquid: theory and experiment. Adv Colloid Interface Sci, 2007, 134-135: 151-166

28 Wang J, Bao W, Umar A, et al. Delaminated layered double hydroxide nanosheets as an efficient vector for DNA delivery. J Biomed Nanotechnol, 2016, 12: 922-933

29 Ge N, Wang D, Peng F, et al. Poly(styrenesulfonate)-modified NiTi layered double hydroxide film: a smart drug-eluting platform. ACS Appl Mater Interfaces, 2016, 8: 24491-24501

30 El Kadi N, Martins F, Clausse D, et al. Critical micelle concentrations of aqueous hexadecytrimethylammonium bromidesodium oleate mixtures. Colloid Polym Sci, 2003, 281: 353-362

31 Repko A, Nižňanský D, Matulková I, et al. Hydrothermal preparation of hydrophobic and hydrophilic nanoparticles of iron oxide and a modification with CM-dextran. J Nanopart Res, 2013,
15: 1767

32 Shim WS, Yoo JS, Bae YH, et al. Novel injectable $\mathrm{pH}$ and temperature sensitive block copolymer hydrogel. Biomacromolecules, 2005, 6: 2930-2934

33 Zhang L, Mohammed EAA, Adriaens A. Synthesis and electrochemical behavior of a magnesium fluoride-polydopamine-stearic acid composite coating on AZ31 magnesium alloy. Surf Coatings Tech, 2016, 307: 56-64

34 Yang Z, Yang Y, Xiong K, et al. Nitric oxide producing coating mimicking endothelium function for multifunctional vascular stents. Biomaterials, 2015, 63: 80-92

35 Madri JA, Stenn KS. Aortic endothelial cell-migration. I. Matrix requirements and composition. Am J Pathol, 1982, 2: 180-186

Acknowledgements This work was financially supported by the Distinguished Young Scholars of China (51525207), the National Natural Science Foundation of China (31570973), the National Key Research and Development Program of China (2016YFC1100604), and Shanghai Committee of Science and Technology, China (15441904900).

Author contributions Liu X conceived and designed the experiments; Peng F performed the experiments and analyzed the data. Peng F and Liu X co-wrote the manuscript. Wang D, Ma X, Zhu H and Qiao Y provided technical guidance and participated in the data analysis.

Conflict of interest The authors declare that they have no conflict of interest.

Supplementary information Supplementary data are available in the online version of the paper. 


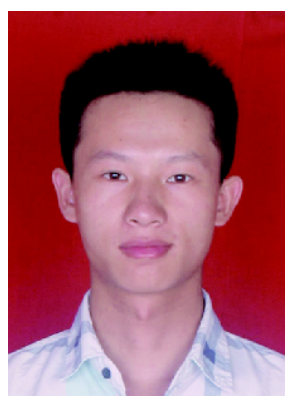

Peng Feng was born in 1992. He received his bachelor degree in materials science from the School of Materials Science and Engineering, Central South University, in 2014. He is now a doctoral candidate at Shanghai Institute of Ceramics Chinese Academy of Sciences, and his current research interest is focused on biodegradable magnesium alloys for biomedical application.

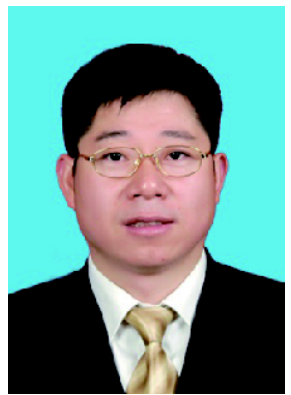

Liu Xuanyong was born in 1974. He received his BSc and MSc degrees in materials science and engineering from Hunan University in 1996 and 1999, respectively, and $\mathrm{PhD}$ in materials science and engineering from Shanghai Institute of Ceramics Chinese Academy of Sciences, in 2002. His research fields include nanosized and functionalized surface of biomedical Ti alloys, PEEK and biodegradable magnesium alloys, surface modification of biomaterials using plasma immersion ion implantation \& deposition (PIII\&D) technology, plasma sprayed bioactive ceramic coatings.

\section{仿花瓣效应超疏水涂层提高纯锠抗腐蚀性和生物相容性}

彭峰 $^{1,2}$, 王东辉 ${ }^{1,2}$, 马小涵 ${ }^{1}$, 朱红芹 $^{1}$, 乔玉琴 ${ }^{1}$, 刘宣勇 $^{1^{*}}$

摘要 由于具有完全可降解性和良好的机械性能, 镁及其合金被誉为“下一代生物医用金属材料”. 然而, 过快的降解速率和较差的生物相 容性制约着它们在临床上的应用. 受“花瓣效应”启发, 本文利用含有油酸钠的溶液, 通过水热法在纯镁表面制备了超疏水且具有高粘附力 的涂层. 涂层表面的片状微纳结构和低表面自由能的油酸根赋予涂层超疏水性. 水滴与涂层表面之间封存的空气以及固液界面间的范德 华力, 使水滴在涂层表面显示出高粘附性(即使倒置 $180^{\circ}$, 水滴也不会从材料表面脱落). 本工作评价了所制备超疏水涂层的化学稳定性和 机械稳定性. 动电位极化曲线和阻抗谱测试都表明所制备涂层具有良好的抗腐蚀性. 此外, 细胞 (人脐静脉内皮细胞)毒性、细胞迁移以及 细胞粘附等结果都表明超疏水涂层具有良好的细胞相容性. 最后, 溶血率和血小板粘附测试表明超疏水涂层的血液相容性也有明显提升. 利用超疏水高粘附力涂层改善纯镁抗腐蚀性和生物相容性的思路有望拓展镁在生物医用领域的应用. 